\title{
The Differential Effects of Positive and Negative Affect on Gratitude After an Intervention
}

\author{
Casey Boyd, Melanie Johnson, Abel Pichardo, Ariana Khayamian, Nicola \\ Schmelzer, Tzu-Chien Lin, and Jose Olivas \\ San Diego Mesa College (CA)
}

Suggested bibliographic reference

Boyd, C., Johnson, M., Pichardo, A., Khayamian, A., Schmelzer, N., Lin, T., \& Olivas, J. (2021). The

differential effects of positive and negative affect on gratitude after an intervention. Psi Beta Journal of Research, 1(1), 23-27. https://doi.org/10.54581/WPPW9019

Abstract

This study sought to explore the relationship between positive and negative affect and the effects of an intervention on gratitude. We used data from the Psi Beta National Research Project to explore positive and negative affect in relation to gratitude and to evaluate the effects of an intervention on gratitude. Using affect to understand gratitude may serve to further our understanding of positive emotions. Perhaps gratitude interventions can have sustainable positive effects. Participants $(N=1,176)$ attending community colleges from across the United States completed the study. Participants completed a questionnaire designed to measure positive affect, negative affect, and gratitude to determine their current level of gratitude. Participants then completed an eight-minute intervention, followed by responding to several more scales and additional items measuring gratitude. Results supported hypotheses that gratitude would positively correlate with positive affect and negatively correlate with negative affect. Researchers hypothesized that, after an appreciation intervention, those scoring high on positive affect would have a larger increase in gratitude than those scoring low on positive affect and that after a frustration intervention, those scoring high on negative affect would have a larger decrease in gratitude than those scoring low on negative affect. These hypotheses were not supported by the findings; on average, gratitude decreased for participants regardless of the intervention type. The intervention was not a significant moderator. Due to the limitations of this study, further research is needed to explore the way that affect may impact gratitude and to consider different types of interventions that may increase gratitude.

Keywords: positive affect, negative affect, gratitude, interventions

During daily life, people often experience emotions such as joy, anger, excitement, fear, sadness, hope, and anxiety. Some people have a greater propensity to experience positive emotions than others, and others have a greater propensity to experience negative emotions. The Positive and Negative Affect Schedule (PANAS) is commonly used to assess one's proclivity for different types of emotions, and a growing body of research 
shows that people scoring high on positive affect reap numerous benefits (Watson et al., 1988). Benefits of experiencing positive emotions include a greater sense of well-being, greater satisfaction with life, more fulfilling relationships, and better physical health (Sheldon \& Lyubomirsky, 2006; Diaz-Garcia, et al., 2020; Stellar et al., 2015). Research has explored ways to increase positive affect by having participants experience positive emotions (Parks \& Schueller, 2014).

Intuitively, there is a relationship between positive affect and gratitude. Therefore, gratitude has been the focus of much research over the last two decades, specifically the biology and benefits of gratitude and ways to increase feelings of gratitude (Allen, 2018). Although there are broad interpretations of gratitude, Emmons and McCullough (2003) explain that gratitude is the result of a two-step cognitive process: recognizing that one has experienced a positive outcome, then recognizing that an external source is responsible for the positive outcome. Emmons and McCullough (2003) found a correlation between gratitude and positive affect. Other empirical evidence shows that cultivating gratitude can lead to an increase in positive affect, which fosters positive benefits such as happiness, well-being, and satisfaction with life (Parks \& Schueller, 2014).

The study replicated previous research that found that positive affect and negative affect correlate with gratitude. This study also explored causation. We hypothesized that people scoring high on positive affect would experience more gratitude in response to a positive intervention compared to those scoring low on positive affect.

\section{Participants}

\section{Method}

The participants $(N=1,176)$ were recruited through convenience sampling from community colleges across the United States. Some participants were offered an incentive through extra credit. The sample included 926 females, 241 males, and 9 who did not specify a gender. The age of participants ranged from 18 to 68 years. All participants were either students or professors at 14 different community colleges.

\section{Materials}

\section{Gratitude Scale}

Emmons and McCullough (2003) created the Assessment of Gratitude measure. Emmons is known for his research on gratitude; his work was published in APA's Positive Psychological Assessment handbook (Lopez \& Snyder, 2003). The scale is a six-question gratitude questionnaire, the GQ-6. The research questionnaire also included a single Likert scale question, "How grateful do you feel right now," as a pre and post gratitude measure.

\section{Positive Affect Negative Affect Schedule}

The Positive Affect Negative Affect Schedule (PANAS) measures emotionality (Watson et al., 1988). This instrument uses two 10-item questionnaires on a Likert scale to measure both positive affect and negative affect. Our measurements used a modified version with four questions for each affect.

\section{Procedure}

IRB approval was obtained by the researchers who designed the study at Irvine Valley College (CA). Next, participating Psi Beta chapters followed their local approval process prior to sampling. Participants were found through instructor recruitment and student recruitment scripts provided by Psi Beta National. Data were collected from October 2020 to February 2021.

The Psi Beta National questionnaire consisted of 216 items. Participants first responded to demographic questions, followed by 14 emotional questions on a 7-point Likert scale. Examples were "To what extent do you feel grateful RIGHT NOW?" and "To what extent do you feel happy RIGHT NOW?" An intervention was randomly assigned using the last digit of each participant's phone number. Participants were directed to one of three intervention videos intended to evoke thoughts of frustration, appreciation, or neither. More specifically, depending on the assigned treatment, participants were instructed to think of 
a person, object, place, and past event they found to be frustrating (treatment 1), appreciated (treatment 2), or neutral (treatment 3 ). The videos were narrated by a female's voice who led participants through their assigned treatment. The instructions were followed by periods of silence lasting between 45 and 60 seconds during which participants were instructed to think about the stimulus item. The intervention was followed by ten 7point Likert items on satisfaction with life and general appreciation. Next came ten questions about self-esteem, six about gratitude, and four questions from the Subjective Happiness Scale (Lyubomirsky \& Lepper 1999).

A modified version of the PANAS was administered pre-intervention with four questions each for positive and negative affect. The PANAS measures affect through self-report. Postintervention, McCullough's (2002) Gratitude Questionnaire (GQ-6) was used to measure gratitude. The GQ-6 is a self-report questionnaire, with six items. The GQ-6 uses a 7-point Likert type scale $(1=$ strongly disagree, 7 = strongly agree $)$. A single item (a self-rating of gratitude) was used as a pre and post intervention gratitude. These scales measured gratitude, happiness, fortunateness, appreciativeness, connectedness, and satisfaction with life. (The complete research questionnaire can be obtained by contacting Psi Beta.)

\section{Results}

The original number of participants totaled 1,243 . Some cases were removed due to incomplete data, reporting an age below 18, and duplicate data from some participants. The final sample included 1,176 cases. SPSS was used to analyze the data file. Pearson's linear coefficient of correlation analyses were conducted between gratitude and positive affect and between gratitude and negative affect. Multiple regression was used to measure the gratitude change after the intervention. Lastly, a comparison on gratitude averages was performed across the three groups preintervention and post-intervention for any change in gratitude.

Figure 1

Scatterplot of Positive Affect and Gratitude

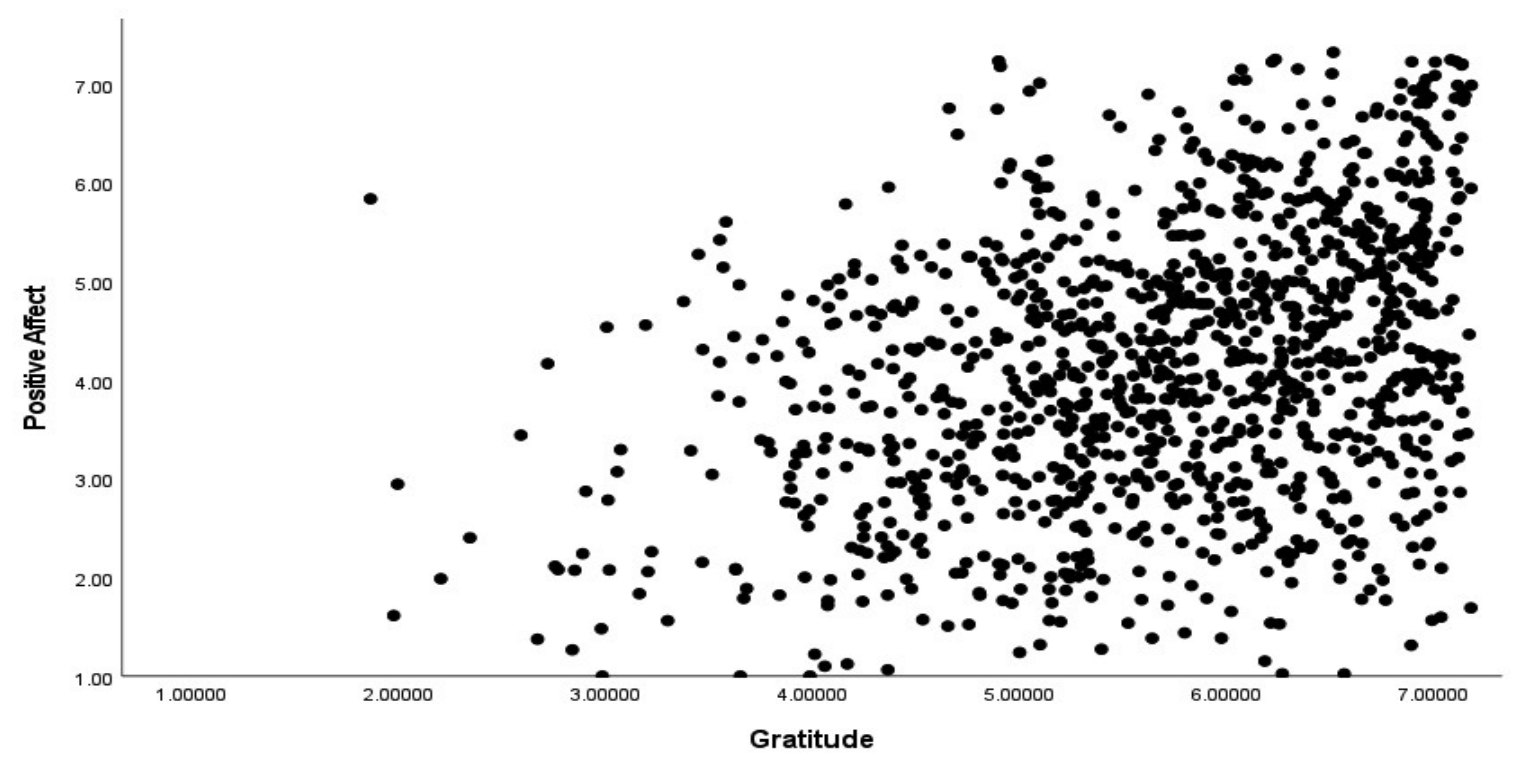


Figure 2

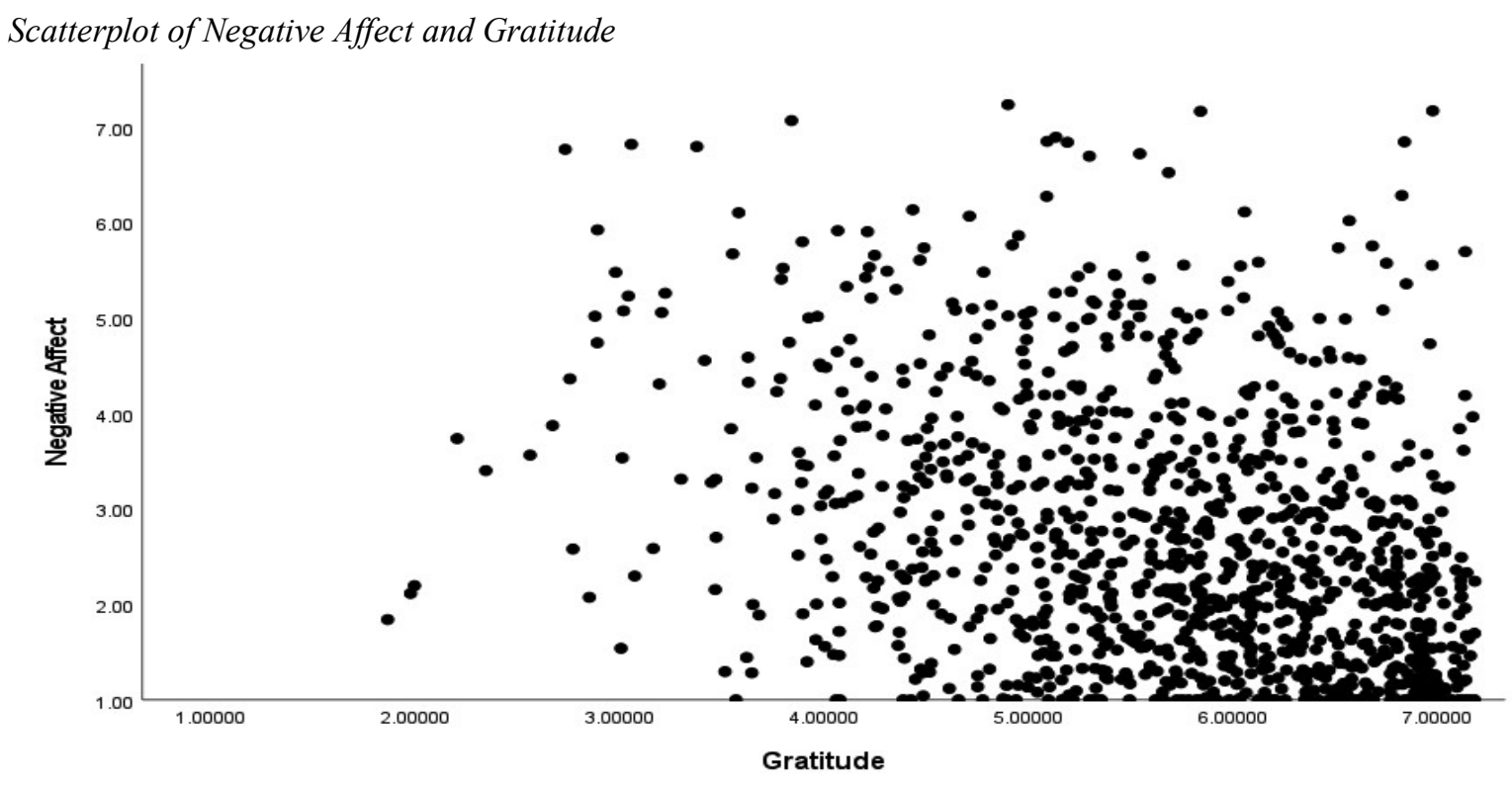

Gratitude (GQ-6) was positively correlated with positive affect pre-intervention $r(1174)=$ $0.35, p<.001$ and negatively correlated with negative affect pre-intervention $r(1174)=-0.33, p<$ .001 . The intervention was not a moderator in the relationship between affect and gratitude.

\section{Discussion}

The hypothesis that positive affect and gratitude would be positively correlated was supported. These findings support previous research (McCullough \& Emmons, 2002; Parks \& Schueller, 2014). The results did not indicate that type of intervention (positive, negative, or neutral) had a significant effect on gratitude. We expected the group receiving the appreciation intervention to have an increase in gratitude. However, the reverse was true; regardless of the type of intervention, participants scored lower in gratitude on average after the intervention.

\section{Limitations}

Previous research shows that brief interventions produce changes of limited duration but that the longer a person participates in activities that cultivate gratitude, the more long-lasting the posi-
001. Regardless of intervention type, the pre to post gratitude change was not significant. Intervention group type, therefore, was not a significant

tive results (Sheldon \& Lyubomirsky, 2007). The intervention in the present study was probably too brief and not sufficiently engaging to produce the hypothesized results. After the intervention, participants were required to answer 139 items prior to assessing gratitude a final time. If participants had felt an increase in gratitude after the appreciation intervention, it may have dissipated by the time they reached the final gratitude item. Fatigue may account for the overall drop in gratitude across the groups. Lastly, there were variations across intervention videos that could have introduced one or more confounds.

\section{Future Research}

Further studies should include randomized variation in pitch or vocal performer to better control for extraneous variables across treatments. Interventions requiring more active engagement from participants should be considered for future research. 


\section{References}

Allen, S. (2018). The science of happiness. [White paper]. Greater Good Science Center at UC Berkeley.https://ggsc.berkeley.edu/images/uploads/GG SC-JTF White Paper-Gratitude-FINAL.pdf

Díaz-García, A., González-Robles, A., Mor, S., Mira, A., Quero, S., García-Palacios, A., Baños, R.M., $\&$ Botella, C. (2020). Positive and Negative Affect Schedule (PANAS): Psychometric properties of the online Spanish version in a clinical sample with emotional disorders. BMC Psychiatry, 20 , 56.https://doi.org/10.1186/s12888-020-2472-1

Emmons, R.A., \& McCullough, M. E. (2003). Counting blessings versus burdens: An experimental investigation of gratitude and subjective wellbeing in daily life. Journal of Personality and Social Psychology, 84(2),377-89. https://doi.org/10.1037//0022-3514.84.2.377

Lopez, S. J., \& Snyder, C. R. (2003). Positive psychological assessment: A handbook of models and measures.

American Psychological Association.

Lyubomirsky, S., \& Lepper, H. (1999). A measure of subjective happiness: Preliminary reliability and construct validation. Social Indicators Research, 46, 137-155

.http://sonjalyubomirsky.com/subjectivehappiness-scale-shs/

McCullough, M. E. (2002). The Gratitude Questionnaire (GQ-6). Retrieved from https://www.midss.org/content/gratitudequestionaire-gq-6

McCullough, M. E., \& Emmons, R.A. (2002). The grateful disposition: A conceptual and empirical topography.

Journal of Personality and Social Psychology, 82(1), 112-27. https://doi.org/10.1037//00223514.82.1.112

Parks, A. C., \& Schueller, S. M. (2014). The Wiley Blackwell handbook of positive psychological interventions.John Wiley \& Sons. www.ketabdownload.com

Sheldon, K. M., \& Lyubomirsky, S. (2006). How to increase and sustain positive emotion: The effects of expressing gratitude and visualizing best possible selves. The Journal of Positive Psychology, 1(2), 73-82 https://doi.org/10.1080/17439760500510676

Stellar, J. E., John-Henderson, N., Anderson, C. L., Gordon, A. M., McNeil, G. D., \& Keltner, D. (2015). Positive affect and markers of inflammation: Discrete positive emotions predict lower levels of inflammatory cytokines. Emotion, 15(2), 129-33. https://doi.org/10.1037/emo0000033

Watson, D., Clark, L.A., \& Tellegen, A. (1988). Development and validation of brief measures of positive and negative affect: The PANAS scales. Journal of Personality and Social Psychology, 54(6), 1063-70. https://doi.org/10.1037/0022$\underline{3514.54 .6 .1063}$ 